\title{
RAPID REMOVAL OF BACTERIAL PATHOGENS USING MAGNETIC IRON OXIDE NANOPARTICLES
}

\author{
Chandraprabha M.N ${ }^{1}$, Ahalya $\mathrm{N}^{2}$, Sharada $\mathrm{B}^{3}$, Kavya Venkat ${ }^{4}$, Pujashree A.K \\ ${ }^{1}$ Department of Biotechnology, M.S. Ramaiah Institute of Technology, Bangalore - 560054, Karnataka, India \\ ${ }^{2}$ Department of Biotechnology, M.S. Ramaiah Institute of Technology, Bangalore - 560054, Karnataka, India \\ ${ }^{3}$ Department of Biotechnology, M.S. Ramaiah Institute of Technology, Bangalore - 560054, Karnataka, India \\ ${ }^{4}$ Department of Biotechnology, M.S. Ramaiah Institute of Technology, Bangalore - 560054, Karnataka, India \\ ${ }^{4}$ Department of Biotechnology, M.S. Ramaiah Institute of Technology, Bangalore - 560054, Karnataka, India
}

\begin{abstract}
Instant removal of bacterial pathogens at ultra-low concentrations offers obvious benefits in various infected systems. Magnetic separation techniques have thus proven to be beneficial than other conventional methods. Compared to magnetic beads used in biological separations, magnetic iron oxide nanoparticles (MIONs) promise high-efficiency owing to their large surface/volume ratios. This paper reports the synthesis of MIONs by solution combustion method and stabilization of the nanoparticles by silica coating. The synthesized nanoparticles were characterized by XRD and FTIR. The efficiency of these nanoparticles in the removal of bacterial species like Escherichia coli, Bacillus subtilis, Pseudomonas aeruginosa and Salmonella paratyphi have been explored. The results obtained demonstrate the potential of MION nanoadsorbants as highly efficient materials for removal of pathogens from various liquid samples.
\end{abstract}

Keywords: Silica-Coated MIONs, Amine Functionalization, Bacterial Pathogens, Electrostatic Interaction

\section{INTRODUCTION}

Bacterial contamination can lead to serious diseases and environmental damage, thus posing as a serious threat to human health and biodiversity. The low infectious dose of bacterial pathogens in food and contaminated water can therefore cause widespread damage. Bacteria at low concentrations are hard to detect and require long induction times. It is well-known that most of the bacteria can double their population in less than 20 min. Therefore, this calls for a rapid capture of bacteria to avoid or minimize the contamination of environment, food, and infections.

Interest in MIONs for capturing bacteria arises from a variety of attributes, including their similar size and magnetic behavior (Saptarshi et al., 2011). Use of MIONs not only facilitates rapid capture of bacteria, but also, aids in their easy separation by the application of a magnetic field.

To meet the objectives of this study, MIONs were synthesized by the method of solution combustion using Glycine as the fuel (Toniolo et al., 2007). The protocols for the study of removal of bacterial pathogens using the synthesized nanoparticles were adopted from Huang et al., 2010 .

\section{MATERIALS \& METHODS}

\subsection{Synthesis of Magnetic Iron Oxide Nanoparticles}

\section{(Solution Combustion Method)}

Combustion method was used to synthesize Iron oxide nanoparticles. In this method, synthesis was carried out by adding $5 \mathrm{gm}$ of Ferric nitrate (precursor) and $1.5485 \mathrm{gm}$ of glycine (fuel) to $25 \mathrm{ml}$ of distilled water. This solution was kept in Muffle Furnace at $300^{\circ} \mathrm{C}$ for $10 \mathrm{~min}$. After combustion, nanoparticles were obtained in the form of delicate fibers, which was then ground to obtain fine nanoparticles. These nanoparticles were then characterized (Kopp Alves et al., 2013).

\subsection{Characterisation Studies}

The nanoparticles were characterised using Fourier transform infrared spectroscopy (BRUKER-ALPHA FT-IR Spectrometer) and $\mathrm{X}$-ray diffraction (JOEL-JDX8030 diffractometer).

\subsection{Bacterial Capture Studies}

The bacterial capture efficiency of the nanoparticles was studied using an UV-VIS spectrophotometer. Distilled water served as blank. The initial bacteria concentration was adjusted to an OD value of 1.0 to maintain uniformity. Nanoparticles were added at concentrations of $1 \mathrm{mg} / \mathrm{ml}, 2$ $\mathrm{mg} / \mathrm{ml}, 3 \mathrm{mg} / \mathrm{ml}$ and $5 \mathrm{mg} / \mathrm{ml}$. The relative efficiencies of the magnetic capture of bacteria by the nanoparticles were calculated from the decrease in turbidity relative to a reference before magnetic capture

\section{RESULTS AND DISCUSSION}

\subsection{Behaviour of Nanoparticles under a Static Magnetic Field}

The nanoparticles in the solution were found to get agglomerated at the point of application of the static 
magnetic field, which was found to be steady for long intervals of time. Upon removal of the field, they dispersed back into solution, confirming super paramagnetism.

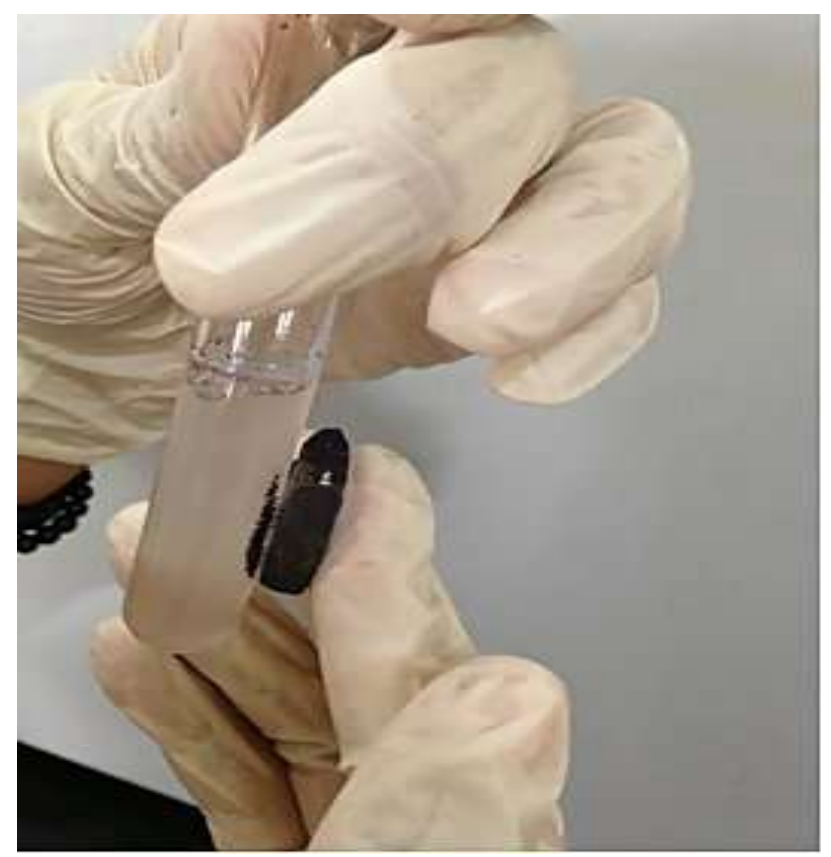

Fig 1: A suspension of MIONs getting attracted to a permanent magnet

\subsection{Fourier Transform Infrared Spectrometry (FTIR)}

The FTIR spectra of plain magnetic iron oxide nanoparticles indicates peaks at $3650 \mathrm{~cm}^{-1}-3200 \mathrm{~cm}^{-1}$ is for $\mathrm{O}-\mathrm{H}$ bond stretching and the peak at $2362 \mathrm{~cm}^{-1}$ is for atmospheric $\mathrm{CO}_{2}$.

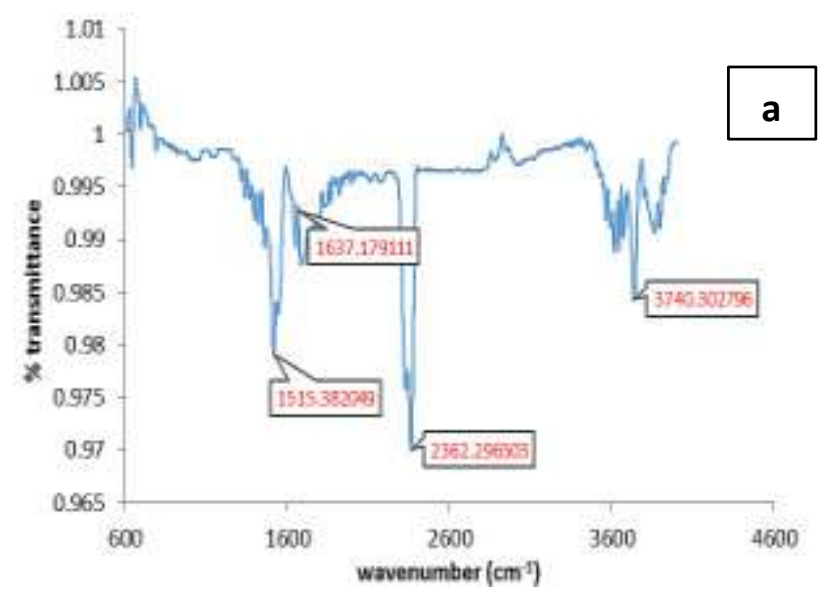

Fig 2: FTIR images of MIONs

\subsection{X-ray Diffraction}

The narrow peaks without much noise in the signal indicate that the nanoparticles are crystalline in nature. A series of characteristic peaks were observed in the XRD pattern at $2 \theta$ of $30.2^{\circ}, 33.16^{\circ}, 35.56^{\circ}, 43.24^{\circ}$ and $62.9^{\circ}$ corresponding to the diffractions of $67^{\circ}, 96^{\circ}, 230^{\circ}, 37^{\circ}$ and $53^{\circ}$ crystal faces of the iron oxide crystal structure.

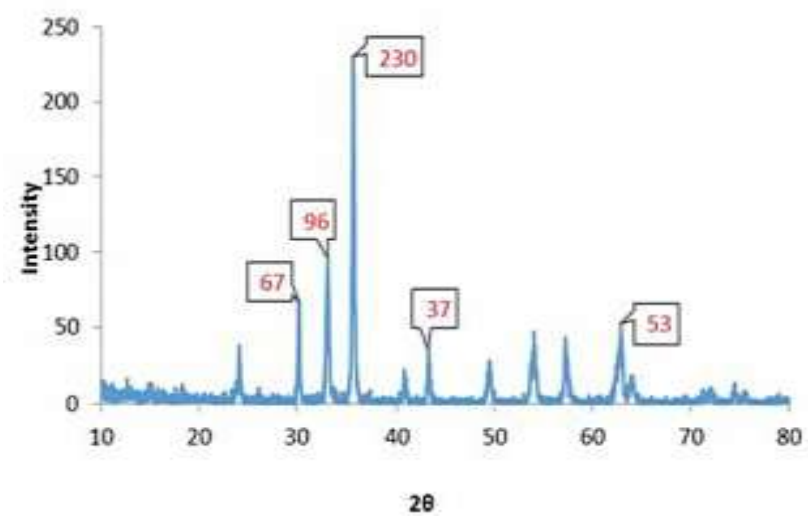

Fig 3: XRD image of MIONs

\subsection{Bacterial Capture Studies}

Rapid aggregation and microbial arrest was noticed in the bacterial solutions. Aggregates of cells and the different nanoparticles precipitated in several minutes in the presence of an external magnet and the supernatant solution became clear. Removal of above $90 \%$ was achieved in less than 5 min for the strains Escherichia coli, Pseudomonas aeruginosa and Salmonella paratyphi. The removal efficiency was lower for Bacillus subtilis. Concentration of nanoparticles did not have significant effect since the concentration of bacteria was less.

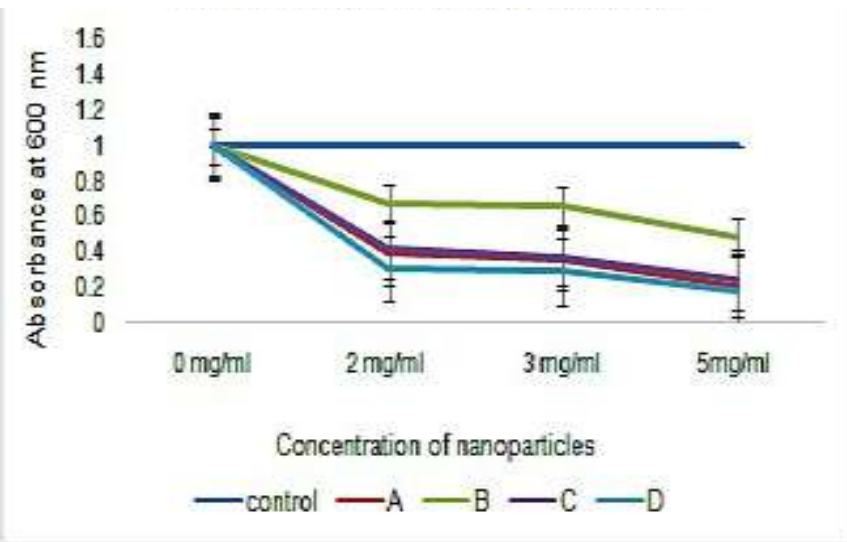

Fig 4: Removal of (A) P. aeruginusa, (B) B. subtilis, (C) E. coli and (D) S. paratyphi with MION nanoparticles.

\section{CONCLUSION}

The structural properties of the synthesized MIONs as analyzed by XRD indicated crystalline structure with diffraction peaks corresponding to iron oxide. The nanoparticles were found to be effective in the removal of both Gram-positive and Gram-negative bacterial species. Removal of above $90 \%$ was achieved in less than $5 \mathrm{~min}$. The results obtained demonstrate the potential of magnetic iron oxide nanoparticless as highly efficient materials for removal of pathogens from various liquid samples. 


\section{REFERENCES}

[1] Saptarshi, C., Arghya, B., Keka, S., (2011). Effect of iron oxide and gold nanoparticles on bacterial growth leading towards biological application. Journal of Nanobiotechnology, 9, 34-39.

[2] Toniolo, J.C., Takimi, A.S., Bonadiman, R., Andrade, M.J., and Bergmann, C.P., (2007). Synthesis by the Solution Combustion Process and Magnetic Properties of Iron Oxide $\left(\mathrm{Fe}_{3} \mathrm{O}_{4}\right.$ and $\left.\alpha-\mathrm{Fe}_{2} \mathrm{O}_{3}\right)$ Particles. Journal of Material Sciences, 42, 47854791.

[3] Huang, Y., Wang, Y., and Yan, X., (2010). AmineFunctionalized Magnetic Nanoparticles for Rapid Culture and Removal of Bacterial Pathogens. Environmental Science and Technology, 44, 79087913.

[4] Annelise, K.A., Carlos, P.B., Felipe, A.B., (2013) Novel Synthesis and Characterization of Nanostructured Materials, Engineering Materials, Springer. 